\title{
The Clinical Applications of Image Guidance in Revision Endoscopic Frontal Sinus Surgery
}

\author{
Ali Almomen ${ }^{1}$ and Muneera AlKhalifa ${ }^{2 *}$ \\ ${ }^{1}$ Consultant Rhinology \& Skull base surgery, King Fahad Specialist Hospital, Kingdom of Saudi Arabia \\ ${ }^{2}$ Bahrain Defense Force Hospital, Bahrain
}

Submission: July 01, 2020; Published: July 23, 2020

*Corresponding author: Muneera Al Khalifa, Bahrain Defense Force Hospital, Bahrain

\section{Abstract}

Background: Frontal sinus disease is obstinate. With its multifaceted anatomy and neighboring vital structures, frontal sinus disease creates a dreaded encounter to every otolaryngologist. Further complicated are revision endoscopic frontal sinus surgeries beside unrecognizable anatomy, revision endoscopic frontal sinus surgeries present technical challenges. The objective is to highlight the causes of revision endoscopic frontal sinus surgery and illustrate the clinical applications of the image guidance in managing them.

Methods: Retrospective review of 60 patients underwent revision endoscopic sinus surgery with image guidance from 2015 to 2019

Results: the causes of revision out of 60 patients $33 \%$ were due to retained uncinate process, residual agger nasi with/without ethmoid disease. Followed by $25 \%$ due to extensive mucosal disease with polyps then $24 \%, 11 \%$ and $5 \%$ presenting lateralized middle turbinate, unopened suprabullar cell and neo-osteogenesis, respectively. All patients were followed up for 3 years with $91.67 \%$ successful patency rate of frontal outflow after revision.

Conclusion: the image guidance in revision endoscopic frontal sinus surgery provides accurate identification of remnant bones or cells that may obscure the outflow. Its further aids in evading recurrence or persistent disease with adequate frontal sinusotomy while protecting vital structures.

Keywords: Frontal sinus; Revision endoscopic sinus surgery; Image guided endoscopic sinus surgery

\section{Introduction}

Frontal sinus surgeries throughout the history have been tiresome. Even in the hands of experts frontal sinus surgeries outcomes have been debatable. The available success rate of primary functional endoscopic sinus surgeries varies from 76$98 \%$ [1]. None the less almost $25 \%$ of operated individuals eventually require revision surgery for unrelenting or recurrent symptoms. Published data by Khalil et al. [2] displayed causes of failure including residual frontal air cells, posterior or anterior ethmoid air cells, residual uncinate process, deviated nasal septum or middle turbinate lateralization [3]. Many of which would contribute to frontal recess blockage where the disease is most probably to reoccur [4]. The purpose of this study is to emphasize the causes of failed primary endoscopic frontal sinus surgeries and illustrate the clinical applications of the image guidance in managing them.

Aim

To study the clinical applications of image guidance in managing the different causes of revision endoscopic frontal sinus surgeries.

\section{Methods and Materials}

Retrospective charts review of 60 patients underwent revision endoscopic frontal sinus surgery with image guidance for chronic recurrent sinusitis with and without polyposis from 2010 to 2019 at a tertiary referral hospital of King Fahad Specialist Hospital Dammam, the eastern province of Saudi Arabia with 4 million population.

\section{Results}

The causes of revision surgery and frontal disease reoccurrence (Table 1) showed variable causes. From the 60 patients reviewed $33 \%$ were due to retained uncinate process, residual agger nasi with/without ethmoid disease. Followed by $25 \%$ due to extensive mucosal disease with polyps then $24 \%, 11 \%$ and $5 \%$ presenting lateralized middle turbinate, unopened suprabullar cell and neoosteogenesis, respectively (Table 1).

All patients were followed up for the period from 1 to 5 years with $91.67 \%$ successful patency rate of frontal outflow after image 


\section{Global Journal of Otolaryngology}

guided endoscopic revision. Few Illustrative cases demonstrating revision endoscopic frontal sinus surgery (Figures 1-9). the value of image guidance in managing different causes of

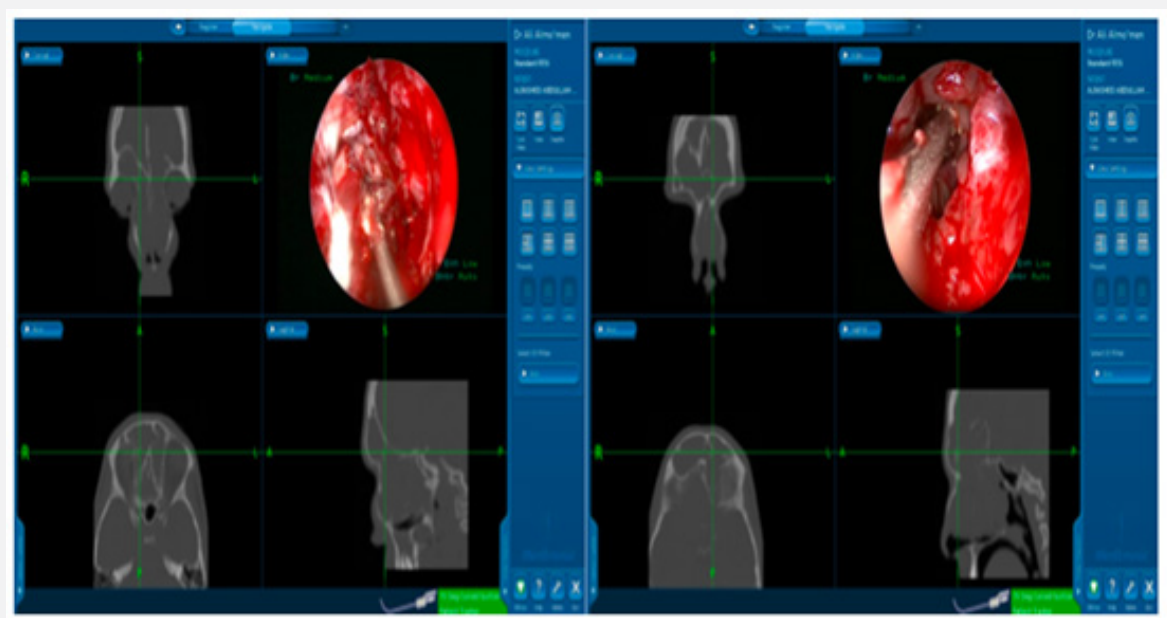

Figure 1: Avoidance of orbital and intracranial injuries.

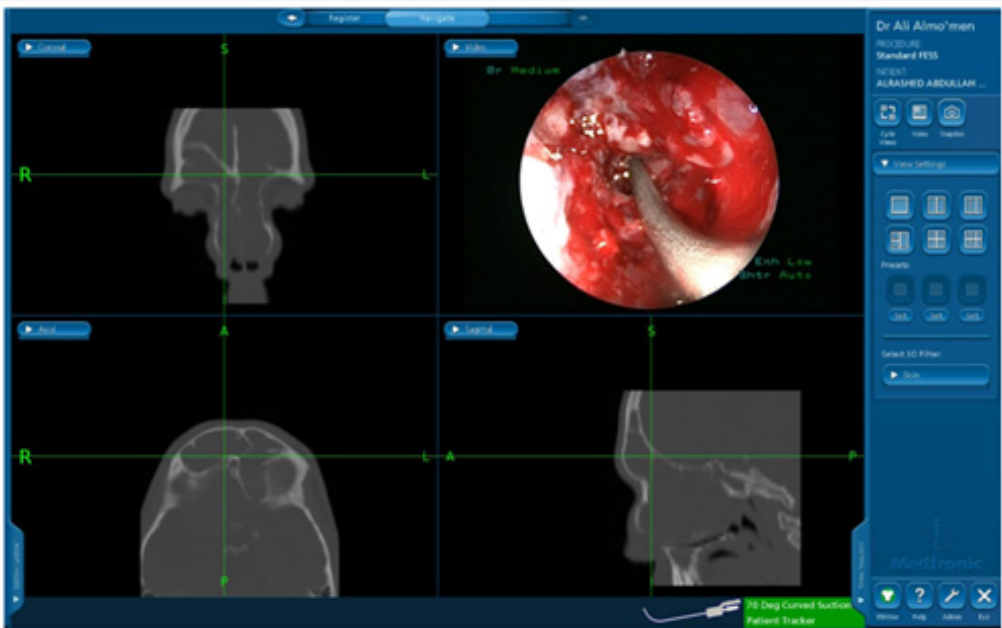

Figure 2: Accurate location of the probe touching the posterior right frontal sinus wall.

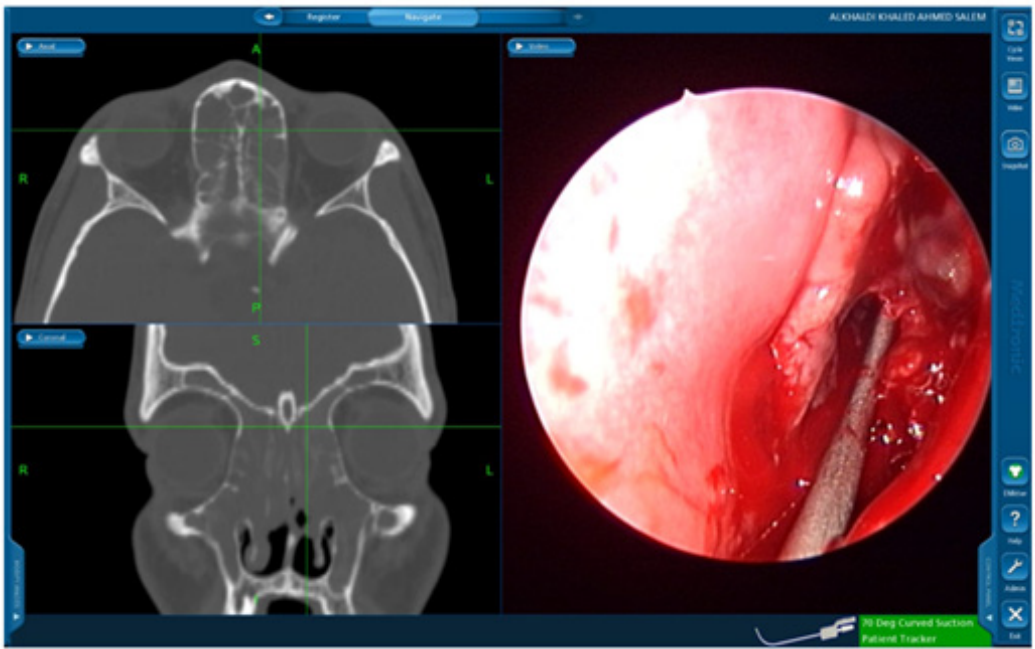

Figure 3: Incomplete dissection of uncinate process. 


\section{Global Journal of Otolaryngology}

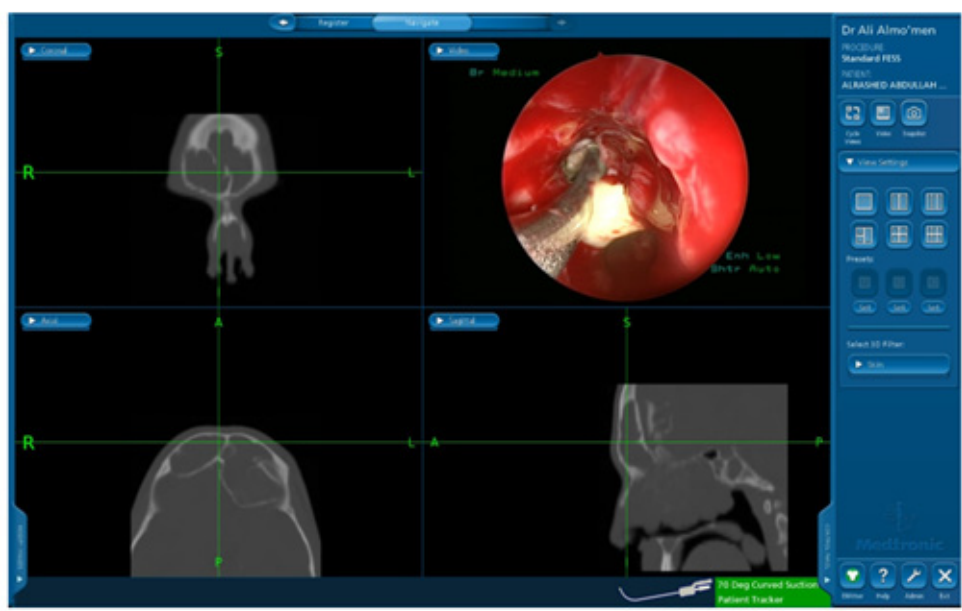

Figure 4: Infected undissected frontal cell.

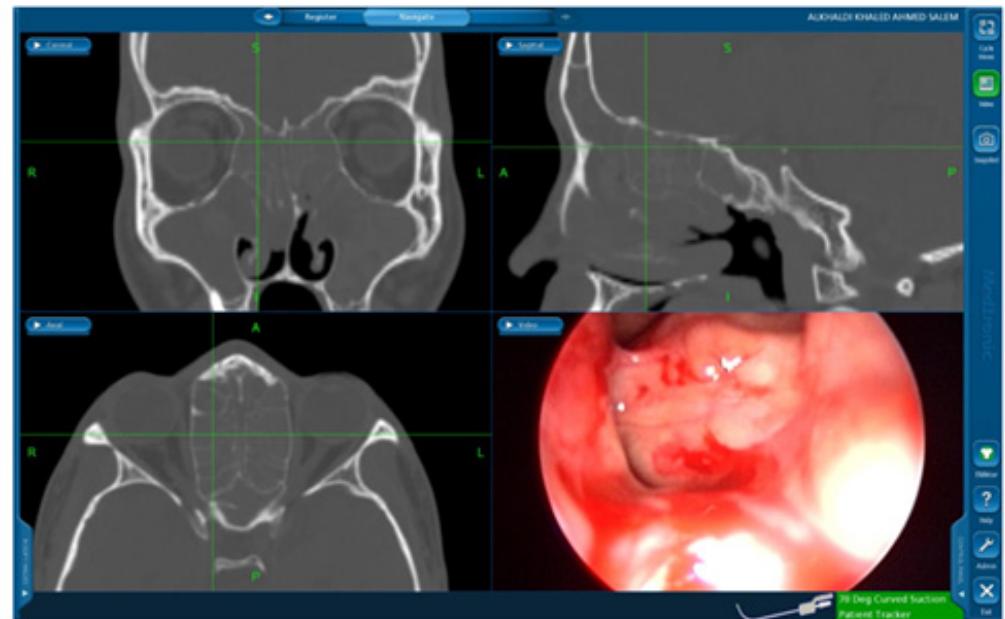

Figure 5: Suprabullar cell dissection.

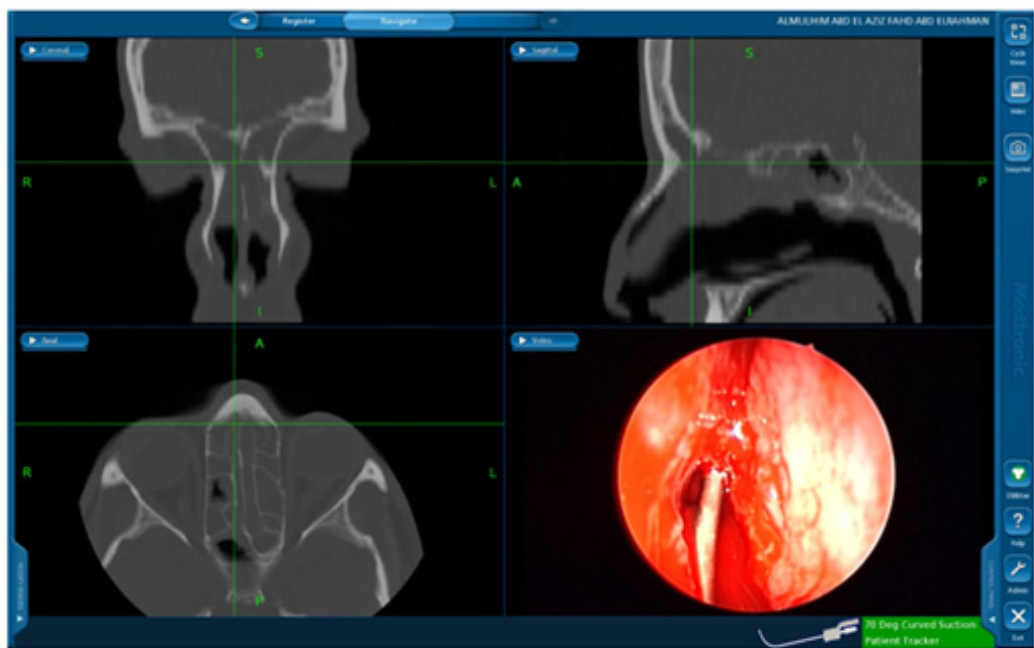

Figure 6: Edematous lateralized middle turbinate. 


\section{Global Journal of Otolaryngology}

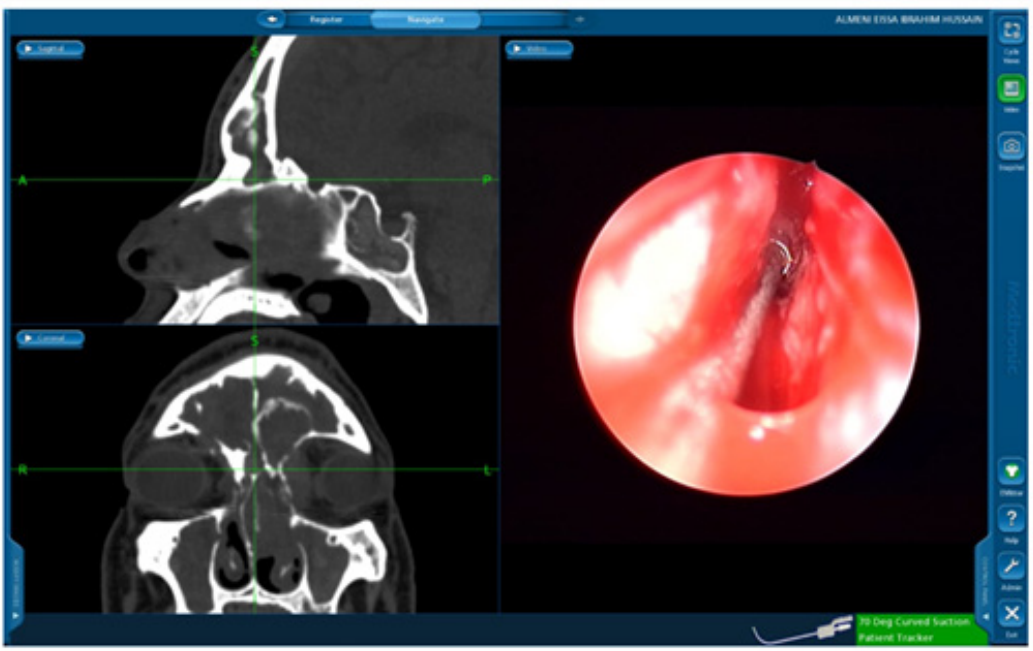

Figure 7:Neoosteogenesis obstructing the frontal sinus flow.

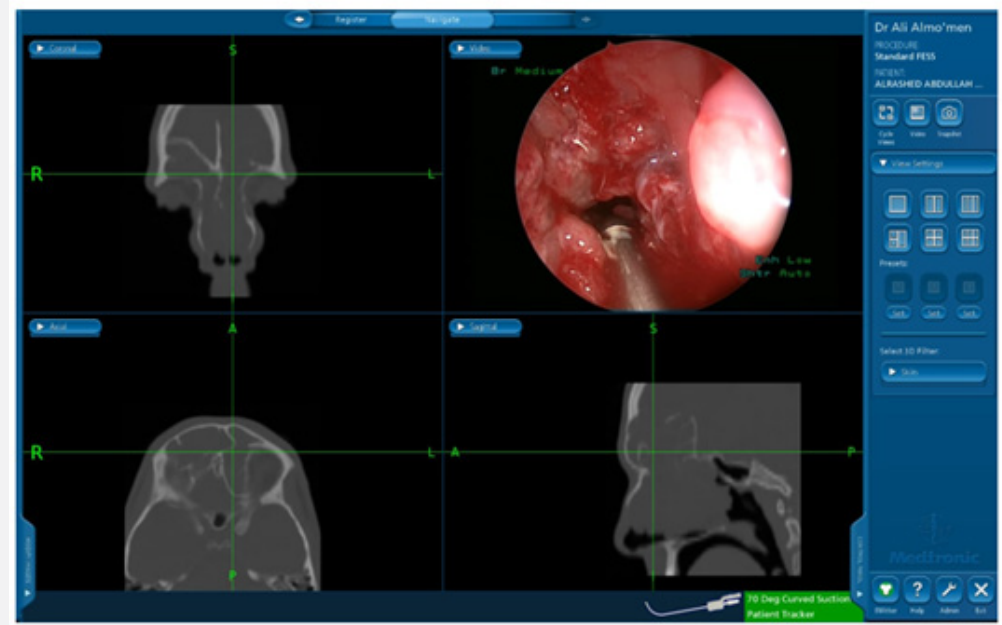

Figure 8: Polyps obstructing frontal sinus flow.

Table 1: The pathological and anatomical causes of revision identified by pre-operative CT scan and intra operative surgical dissection summarized.

\begin{tabular}{|c|c|c|}
\hline & Etiology & No. of Cases \\
\hline 1 & Retained uncinate process, residual agger nasi with/ without ethmoid disease & $20(33 \%)$ \\
\hline 2 & Extensive mucosal disease with polyps obstructing the frontal recess & $15(25 \%)$ \\
\hline $3 \mathrm{a}$ & Lateralized middle turbinate with/without frontal recess scarring & $8(13 \%)$ \\
\hline $3 \mathrm{~b}$ & Lateralized middle turbinate with residual uncinate process or agger nasi cell & $7(11 \%)$ \\
\hline 4 & Unopened suprabullar cell with/without frontal cells & $7(11 \%)$ \\
\hline 5 & Neo-osteogenesis complete frontal recess bony obstruction & $3(5 \%)$ \\
\hline
\end{tabular}

\section{Discussion}

Frontal sinus surgeries present a challenge due to its unique outflow anatomy. Resting between vital structures as the orbit and base of skull attaining an adequate outflow whilst avoiding complications is a trial. The complexity of frontal recess air cells presents another obstacle in the goal of achieving flow. Whilst taking in consideration these difficulties in a primary case frontal 
sinusitis in a revision case magnifies the challenge. Interpreting the cause of reoccurrence needs thorough evaluation of the patient's radiological and clinical evaluation. A CT scan should be performed in all patients after 4-6 weeks of medical treatment trial and avoidance of imaging during an acute upper respiratory tract infection is also advisable [4].

Since its development in the 1980s in Germany image guidance immerged a new platform for otolaryngologist. Contiguous $1 \mathrm{~mm}$ thickness CT scan slices with 3-D reconstruction aids in diagnosing and providing accurate localization of bony partitions and boundaries [5,6]. In a study conducted by Loehrl et al. 31 patients underwent revision endoscopic frontal sinus surgery with image guidance with an average 11.9 months follow up. The authors commended that integrated instruments make revision frontal sinus surgeries efficient by utilizing the instrument after immediate localization has been accomplished [7].

Such accuracy is demonstrated in the illustrated cases in Figure $1 \& 2$ where in Figure 1 the navigation aided in surgeon's advancement in the narrow areas between the orbit and skull base easing the technical challenge. And Figure 2 shows precise localization of the integrated probe touching the frontal sinus posterior wall. The benefit of image guidance can help in the diagnosis of the causes of frontal outflow blockage. In literature recurrent frontal disease can have variable causes highest being incomplete removal of uncinate process or air cells, iatrogenic injury or recurrent mucosal edema or frontal ostium stenosis [8].

Where is Valdes et al reported the findings in recurrent frontal disease in 66 patients to be hypertrophic mucosa $(92.7 \%)$; retained agger nasi cell (73.4\%); neo-osteogenesis within the frontal recess $(45.9 \%)$; lateral scarring of the middle turbinate (47.7\%); residual anterior ethmoid air cell (32.1.\%); and residual frontal cells (24.8\%) [9].

In the 60 patients reviewed the most common cases of frontal sinostomy failure were due to retained uncinate process, residual agger nasi with/without ethmoid disease (33\%). Figure 3 \& 4 display cases of retained uncinate process and undissected frontal air cell, respectively. Bradely et al. [10] recognized agger nassi cell in $93 \%$ of CT scan slides of their revision functional endoscopic sinus patients [10]. Whereas Nakayama et al also concluded through CT scan slide revision that residual frontal recess cells were independent risk factors for postoperative frontal sinusitis [11].

Suprabullar cells are also a recognizable cause of recurrence where is can be wronged for base of skull during primary surgery and left untouched [12]. That represents $11 \%$ of the findings in the revision cases in this study such as the illustrated case in Figure 5. In another recognizable cause $24 \%$ of the revised patients had lateralization of the middle turbinate Figure 6 . This lateralization was found to be due to scarring between the turbinate and retained air cells or uncinate process $13 \%, 11 \%$ respectively. Other causes include neo-osteogenesis, which believed to be caused by failure to preserve normal mucosa [13]. Neo-osteogenesis as seen in Figure 7 presented $5 \%$ of our findings.

Even recurrence of the mucosal disease itself that is seen in Figure 8 presented as a cause of recurrence in $25 \%$ of our revised cases. Although higher rates have been reported in literature where Valdes et al. [9] reported a rate as high as $92.7 \%$ of edematous or hypertrophic mucosa found in CT scan of revised cases.

\section{Conclusion}

In conclusion, frontal sinus outflow presents a challenging technical surgery for all otolaryngologists. That difficulty is magnified in revision cases where anatomy is distorted and recognition of causes of failure is demanding. Image guidance is prized instrument in preforming such cases. Thorough dissection of all remnant bony partitions in the frontal recess is achievable with the assistance of image guidance. Achieving maximum drainage with preservation of vital structures is easily attained with accurate localization provided with image guidance.

\section{References}

1. Musy PY, Kountakis SE (2004) Anatomic findings in patients undergoing revision endoscopic sinus surgery. Am J Otolaryngol 25(6): 418-422.

2. Schaitkin B, May M, Shapiro A, Fucci M, Mester SJ (1993) Endoscopic sinus surgery: 4-year follow-up on the first 100 patients. Laryngoscope 103(10): 1117-1120.

3. Khalil HS, Eweiss AZ, Clifton N (2011) Radiological findings in patients undergoing revision endoscopic sinus surgery: a retrospective case series study. BMC Ear Nose Throat Disord 11: 4.

4. Kennedy DW, Senior BA (1997) Endoscopic sinus surgery. A review. Otolaryngol Clin North Am 30(3): 313-330.

5. L Klimek, R Mösges, G Schlöndorff, W Mann (1998) Development of Computer-Aided Surgery for Otorhinolaryngology. Comput Aided Surg 3(4): 194-201.

6. Bansal M (2000) Computer-assisted functional endoscopic sinus surgery (c-a fess) - a review. Indian J Otolaryngol Head Neck Surg 52(3): 311-314.

7. Loehrl A, Toohill RJ, Smith TL (2000) Use of Computer-Aided Surgery for Frontal Sinus Ventilation. Laryngoscope 110: 1962-1967.

8. Orlandi RR, Kennedy DW (2001) Revision endoscopic frontal sinus surgery. Otolaryngol Clin North Am 34(1): 77-90.

9. Valdes CJ, Bogado M, Samaha M (2014) Causes of failure in endoscopic frontal sinus surgery in chronic rhinosinusitis patients. Int Forum Allergy Rhinol 4: 502-506.

10. Bradley DT, Kountakis SE (2004) The Role of Agger Nasi Air Cells in Patients Requiring Revision Endoscopic Frontal Sinus Surgery. Otolaryngol Head Neck Surg 131(4): 525-527.

11. Nakayama T, Asaka D, Kuboki A, Okushi T, Kojima H (2018) Impact of residual frontal recess cells on frontal sinusitis after endoscopic sinus surgery. Eur Arch Otorhinolaryngol 275(7): 1795-1801. 
12. Kew J, Rees GL, Close D, Sdralis T, Sebben RA, et al. (2002) Multiplanar reconstructed computed tomography images improves depiction and understanding of the anatomy of the frontal sinus and recess. Am J Rhinol 16(2): 119-123.
13. McLaughlin RB Jr, Rehl RM, Lanza DC (2001) Clinically relevant frontal sinus anatomy and physiology. Otolaryngol Clin North Am 34(1): 1-22.

\section{Your next submission with Juniper Publishers will reach you the below assets}

- Quality Editorial service

- Swift Peer Review

- Reprints availability

- E-prints Service

- Manuscript Podcast for convenient understanding

- Global attainment for your research

- Manuscript accessibility in different formats ( Pdf, E-pub, Full Text, Audio)

- Unceasing customer service

Track the below URL for one-step submission https://juniperpublishers.com/online-submission.php 